\title{
A high performance NiCoCrAIY bond coat manufactured using laser powder deposition
}

DOI:

10.1016/j.corsci.2017.07.018

\section{Document Version}

Accepted author manuscript

Link to publication record in Manchester Research Explorer

\section{Citation for published version (APA):}

Luo, L., Shan, X., Zou, Z., Zhao, C., Wang, X., Zhang, A., Zhao, X., Guo, F., \& Xiao, P. (2017). A high performance NiCoCrAlY bond coat manufactured using laser powder deposition. Corrosion Science. https://doi.org/10.1016/j.corsci.2017.07.018

\section{Published in:}

Corrosion Science

\section{Citing this paper}

Please note that where the full-text provided on Manchester Research Explorer is the Author Accepted Manuscript or Proof version this may differ from the final Published version. If citing, it is advised that you check and use the publisher's definitive version.

\section{General rights}

Copyright and moral rights for the publications made accessible in the Research Explorer are retained by the authors and/or other copyright owners and it is a condition of accessing publications that users recognise and abide by the legal requirements associated with these rights.

\section{Takedown policy}

If you believe that this document breaches copyright please refer to the University of Manchester's Takedown Procedures [http://man.ac.uk/04Y6Bo] or contact uml.scholarlycommunications@manchester.ac.uk providing relevant details, so we can investigate your claim.

\section{OPEN ACCESS}




\title{
A High Performance NiCoCrAlY Bond Coat Manufactured Using Laser Powder Deposition
}

Lirong Luo ${ }^{\text {a, b }}$, Xiao Shan ${ }^{\text {a, b }}$, Zhonghua Zou ${ }^{\text {a, b }}$, Chunshan Zhao ${ }^{\text {a, b }}$, Fangwei Guo ${ }^{\text {a, b }}$, Xin Wang ${ }^{c}$, Aiping Zhang ${ }^{c}$, Xiaofeng Zhao ${ }^{\text {a, b, }}{ }^{*}$ and Ping Xiao ${ }^{\text {d, a }}$

${ }^{a}$ Shanghai Key Laboratory of Advanced High-temperature Materials and Precision Forming, Shanghai Jiao Tong University, Shanghai 200240, China

${ }^{b}$ Institute of Gas Turbine, Shanghai Jiao Tong University, Shanghai 200240, China

${ }^{c}$ Konca Solar Cells Co., Ltd, Wuxi 214000, China

${ }^{d}$ School of Materials, University of Manchester, Grosvenor Street, Manchester M1 $7 H S, U K$

\begin{abstract}
A high performance NiCoCrAlY bond coat with dense dendritic microstructure was fabricated using laser powder deposition (LPD) technique. The thermally grown oxides (TGO) formed on the coating deposited by laser powder deposition is predominantly alumina instead of the mix oxides usually formed on the coatings prepared by air plasma spray and high velocity air fuel. Isothermal oxidation tests performed at $1150{ }^{\circ} \mathrm{C}$ reveal that the LPD bond coat shows significantly better spallation resistance and lower TGO growth rate. The superior spallation resistance of the TGO is further discussed in relation to the unique microstructure of the LPD bond coat.
\end{abstract}

*xiaofengzhao@sjtu.edu.cn Tel./fax:+86-21-54742561. 
Keywords: A. Metal coatings; B. Photoluminescence pizeospectroscopy; B. SEM; C. Oxidation.

\section{Background}

Thermal barrier coatings (TBCs) are widely applied in combustors or turbines to increase the gas temperature, thereby the engine efficiency, without increasing the temperature of the superalloy components [1]. TBCs typically consist of an yttria stabilized zirconia (YSZ) top coat and an intermediate metallic bond coat layer. During high temperature service, the thermally grown oxides (TGO) developed between the bond coat and top coat interface, providing oxidation and corrosion resistance of the superalloy components and adherence of the ceramic layer [2]. Upon cooling, the elastic energy in TGO associated with the mismatch of the thermal coefficient of expansion is the main driving force for the failure of the coating system [3]. The strain energy increases with the thickening of TGO. Eventually, when the interfacial stress exceeds the interface toughness, delamination will occur along the interface of the TGO/bond coat or the top coat/TGO and cause the failure of TBCs. [4]. Therefore, the performance of the TGO is critical for the durability of TBCs. A dense and homogenous $\alpha-\mathrm{Al}_{2} \mathrm{O}_{3}$ layer is desirable for the TGO due its low oxygen diffusivity and superior adherence [3]. While the composition and morphology of the TGO is significantly influenced by the properties of the bond coat such as the chemical composition, microstructure, oxides content, thickness $[5,6]$.

The MCrAlY ( $\mathrm{M}=\mathrm{Ni}$, Co or both) bond coats are typically fabricated by air plasma spray (APS), high velocity oxygen-fuel, low pressure plasma spray and electric beam physical vapor deposition. However, no matter what method is used, the most desirable bond coat is one with limited oxygen uptake and dense microstructure [7]. The oxide inclusions in coatings were reported to increase the TGO growth rate and lead to the premature failure $[8,9]$. MCrAlY coatings deposited by APS and high velocity oxygen-fuel exhibit high transient oxide content due to the high temperature 
during the deposition process. Besides, the cost of the low pressure plasma spray and vacuum plasma spray is expensive. In comparison, the LPD method by injecting powder with the laser coaxially under the protection of inert gas could fabricate dense metal coating with few defects and low oxygen content, which are beneficial for the stability of TGO. Meanwhile, the LPD method shows great potential in depositing coatings on the component with small size and complicated geometries, therefore could be used to offer advantages for the repair of turbine blades [10]. Up to now, a few literatures on the oxidation behavior of the MCrAlY coatings fabricated by laser cladding which exhibits dense microstructure similar to the coatings fabricated by LPD, have been reported $[11,12]$. It shows that these coatings are able to form a continuous and stable alumina TGO layer that could act a desirable blocking layer for oxygen diffusion $[13,14]$. However, the oxidation resistance and failure mechanism of the coatings deposited by the laser method have not been systematically investigated and compared with the MCrAlY bond coats fabricated with conventional methods such as APS and high velocity air fuel (HVAF) .

In the present work, we reported to use the LPD method to fabricate NiCoCrAlY bond coat for thermal barrier coating applications. The microstructure, oxidation and spallation behavior of the LPD bond coat were investigated and compared with the bond coats prepared by APS and HVAF. The isothermal oxidation experiment was carried out at $1150{ }^{\circ} \mathrm{C}$ which demonstrates that the LPD bond coat shows much better oxidation resistance and spallation resistance over the bond coat prepared by APS and HVAF. Meanwhile, the mechanisms of the improved oxidation resistance and spallation resistance of the LPD bond coat are discussed.

\section{Experimental procedure}

\subsection{Material and sample preparation}

Nickel-based Hastelloy ${ }^{\circledR}$ X polycrystalline superalloy $\left(50 \times 40 \times 5 \mathrm{~mm}^{3}\right)$ was used as the substrate material, which was grit blasted with grade 30 alumina powder and degreased by ultrasonic clean in acetone. Three types NiCoCrAlY (Amdry 365-2, 
Sulzer Metco Inc., USA) bond coats, prepared by APS, HVAF and LPD, were coated on the substrate with thickness about $200 \mu \mathrm{m}$. The nominal compositions of the Hastelloy® X substrate and NiCoCrAlY powder are listed in Table 1. The APS and HVAF process parameters used in bond coat fabrication are shown in Table 2. The LPD was conducted with continuous wave laser (YLS-2000, IPG America). The diameter of the laser is $500 \mu \mathrm{m}$ after focused by a lens with $200 \mathrm{~mm}$ focal length. The NiCoCrAlY powder was delivered by coaxial feeding nozzles with $10 \mathrm{~mm} / \mathrm{s}$ scan velocity and $3 \sim 4 \mathrm{~g} / \mathrm{min}$ feed rate. The coating was achieved through layer-by-layer scanning and the overlapping ratio between scans was $25 \%$. Inert gas (Ar) was used as the shielding and powder carrier gas to avoid oxidation during the deposition process.

Table 1 Nominal composition of Hastelloy ${ }^{\circledR}$ X substrate and NiCoCrAlY powder.

\begin{tabular}{lccccccccccc}
\hline & \multicolumn{10}{c}{ Element (wt.\%) } \\
\cline { 2 - 5 } & $\mathrm{Ni}$ & $\mathrm{Co}$ & $\mathrm{Cr}$ & $\mathrm{Al}$ & $\mathrm{Y}$ & $\mathrm{Fe}$ & $\mathrm{Mo}$ & $\mathrm{W}$ & $\mathrm{C}$ & $\mathrm{Mn}$ \\
\hline Hastelloy $\mathrm{X}$ & 47 & 1.5 & 22 & $/$ & $/$ & 18 & 9 & 0.6 & 0.1 & $1 *$ \\
\hline NiCoCrAlY & 47.5 & 23 & 17 & 12 & 0.5 & $/$ & $/$ & $/$ & $/$ & $/$ \\
\hline
\end{tabular}

Table 2 Parameters of the APS and HVAF process.

\begin{tabular}{lll}
\hline Processing parameters & APS & HVAF \\
\hline Spray distance $(\mathrm{mm})$ & 90 & 185 \\
Spray speed $(\mathrm{mm} / \mathrm{s})$ & 500 & 2000 \\
Powder rate $(\mathrm{g} / \mathrm{min})$ & 10 & 100 \\
Primary gas $(\mathrm{L} / \mathrm{min})$ & 90 & 77 \\
Secondary gas $(\mathrm{L} / \mathrm{min})$ & 15 & 22.3 \\
\hline
\end{tabular}




\subsection{Isothermal oxidation}

The deposited specimens were cut into rectangular plates with a dimension of $10 \times 10 \times 5 \mathrm{~mm}^{3}$. Then all the bond coats were mechanically ground down to similar thickness $(\sim 150 \mu \mathrm{m})$, polished to a $0.1 \mu \mathrm{m}$ finish and thoroughly cleaned with acetone prior to oxidation. The isothermal oxidation experiment was performed at $1150{ }^{\circ} \mathrm{C}$ in a chamber furnace for duration ranging from 0.5 to $100 \mathrm{~h}$. The specimens were moved into the furnace at $1150{ }^{\circ} \mathrm{C}$. After oxidation for a certain time, the specimens were removed from the furnace and air-cooled to room temperature.

\subsection{Characterization}

The scanning electron microscope (SEM, FEI Quanta 200, Netherlands) was employed to determine the microstructure and thickness of the bond coat and TGO layer after isothermal oxidation. Image analysis was used to measure the area percentage of pores and crack networks of the bond coat. At least 10 micrographs with magnification of $1000 \times$ on the polished surface of as-deposited coatings were used for the porosity determination. The phase composition and element distribution of the bond coat and TGO were analyzed by X-ray diffraction (XRD, Ultimo IV, Riau, Japan) and energy dispersive X-ray spectroscopy (EDS), respectively. The ratio of detached area to the total area of the TGO which is defined as the spallation degree, was measured by optical microscope (BX-51M, Olympus, Japan) based on the contrast between the adhesive and separated region. The acquired images of the TGO surface were analyzed using the image processing software (Image J, NIH).

The residual stress in the TGO was measured using the photoluminescence piezospectroscopy method, by acquiring the stress-induced frequency shift of the R2 line of $\mathrm{Cr}^{3+}$ incorporated in the $\alpha-\mathrm{Al}_{2} \mathrm{O}_{3}$ scales. This experiment was carried out using a confocal Raman microprobe (LabRAM HR, Horiba Jobin Yvon, France) in conjunction with a Olympus microscope. During the measurement, a laser beam $(\mathrm{Nd}: Y A G, 532 \mathrm{~nm})$ was focused on the surface of the TGO layer and the laser spot was about $3 \mu \mathrm{m}$ in diameter. The collected spectra were fitted with a 
Gaussian-Lorentzian Function using Labspec software. The frequency shift was obtained using stress free reference recorded from the unstrained sapphire.

\section{Results}

\subsection{As-prepared microstructure and phase analysis}

Scanning electron micrographs of the cross-section of the NiCoCrAlY bond coats prepared by APS, HVAF and LPD after polishing, are shown in Fig.1. The thicknesses of the bond coats are all about $150 \mu \mathrm{m}$. Usually, the LPD process is accompanied by local inter-diffusion between the coating and the substrate, which hinders the direct measurement of the actual thickness of the LPD bond coat. In this study, the thickness of the polished LPD bond coat was measured by the thickness difference between the area with and without coating.

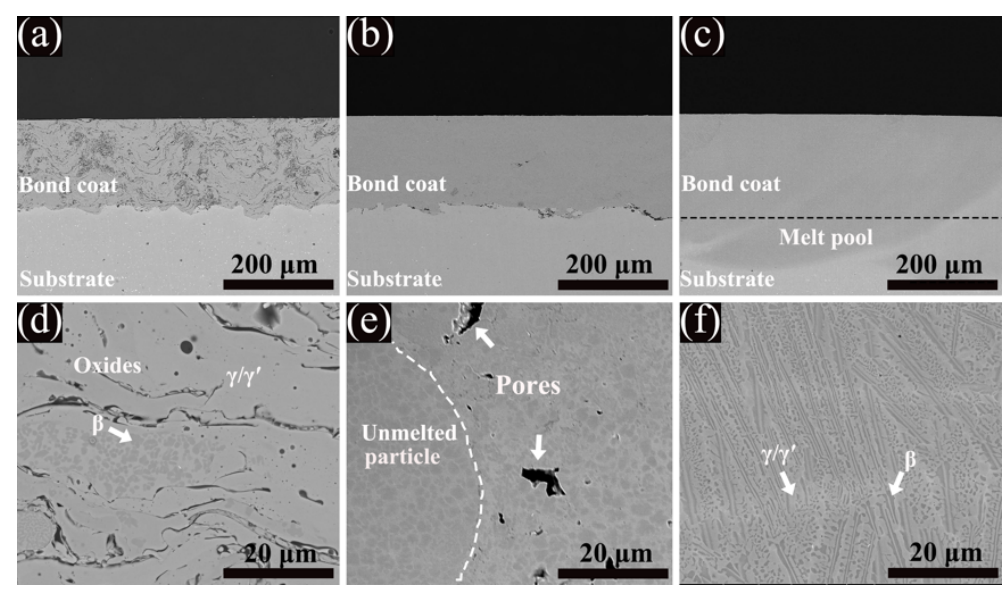

Fig. 1 The cross-sectional SEM micrographs of the bond coats deposited by $(a, d)$ APS, (b, e) HVAF and (c, f) LPD, after surface polished.

The APS bond coat (Fig. 1a and d) shows typical lamellar structure with inter-splat pores, micro-cracks and oxide stringers. For HVAF bond coat (Fig. 1e), a small number of voids and cracks occur along the unmelted particle boundaries, or between adjacent particles attributed to insufficient localized plastic deformation during deposition. The LPD bond coat (Fig. 1f) exhibits a dendritic structure and is almost fully dense expect for minor quantity of pores. In general, the LPD bond coat shows the densest microstructure. This phenomenon is more obvious in the micrographs of 
the polished surface as shown in Fig. 2. On the polished surface, the porosities and micro-crack were quantitative analyzed using image analysis following the literature [15], and the results are summarized in Fig. 2d. The average porosity of APS, HVAF and LPD bond coat is estimated to be about $10.7 \%, 3.32 \%$ and $0.32 \%$, respectively. This observation demonstrates that the bond coat deposited by LPD features the most desirable structure with minimal pores and absence of cracks.
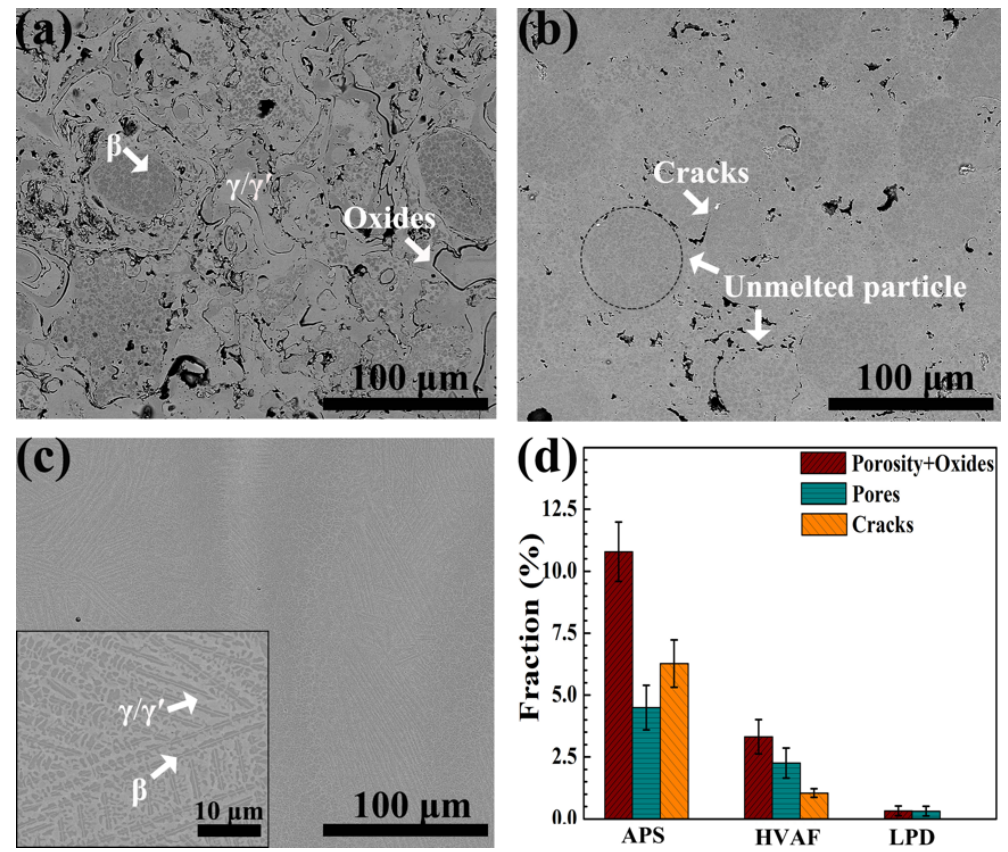

Fig. 2 The microstructure of polished surface of (a) APS, (b) HVAF and (c) LPD bond coats; (d) the porosity summarized based on image analysis. The scale bar shows the standard deviation .

From high magnification SEM micrographs shown in Fig. 2, it is evident that the NiCoCrAlY bond coat manufactured by the three methods all consist of two phases, where the bright zone corresponds to the $\gamma$ matrix phase and the gray zone corresponds to the $\beta$-NiAl phase. The two phases are confirmed by the XRD results. The $\beta$-NiAl phase is granular and disappears near defects such as the splat boundaries, voids, oxides stringers and around unmelted particles in APS and HVAF bond coats. In LPD bond coat, $\beta$-NiAl phase is more homogenous and exhibits a dendritic structure and the grain size is much smaller than that in HVAF and APS bond coats. The finer-grained NiCoCrAlY could be desirable for the homogenous growth of 
alumina by selective oxidation [16]. In summary, compared with the bond coats prepared by APS and HVAF, the LPD bond coat shows the densest microstructure and homogenously distributed $\beta$-NiAl phase.

\subsection{Spallation resistance}

To evaluate the oxidation resistance of the bond coats deposited by different methods, isothermal oxidation tests were carried out at $1150{ }^{\circ} \mathrm{C}$. The spallation degree of the samples as a function of the oxidation time is summarized in Fig. 3. Each data is the average of 9 measurements and the error bar shows the standard deviation. For APS bond coat, exposed metal surface is observed after $10 \mathrm{~h}$ oxidation. The detached area increases dramatically with the oxidation time and reaches $\sim 80 \%$ of the total area when the oxidation time is up to $50 \mathrm{~h}$. While for the HVAF bond coat, the detachment of the TGO appeared after $30 \mathrm{~h}$ and the spallation degree is about $40 \%$ after $100 \mathrm{~h}$. However, the oxide scale is almost intact on LPD bond coat even after $100 \mathrm{~h}$ exposure. The isothermal oxidation tests at $1150{ }^{\circ} \mathrm{C}$ reveal that the LPD bond coat exhibits better spallation resistance than APS and HVAF bond coats.

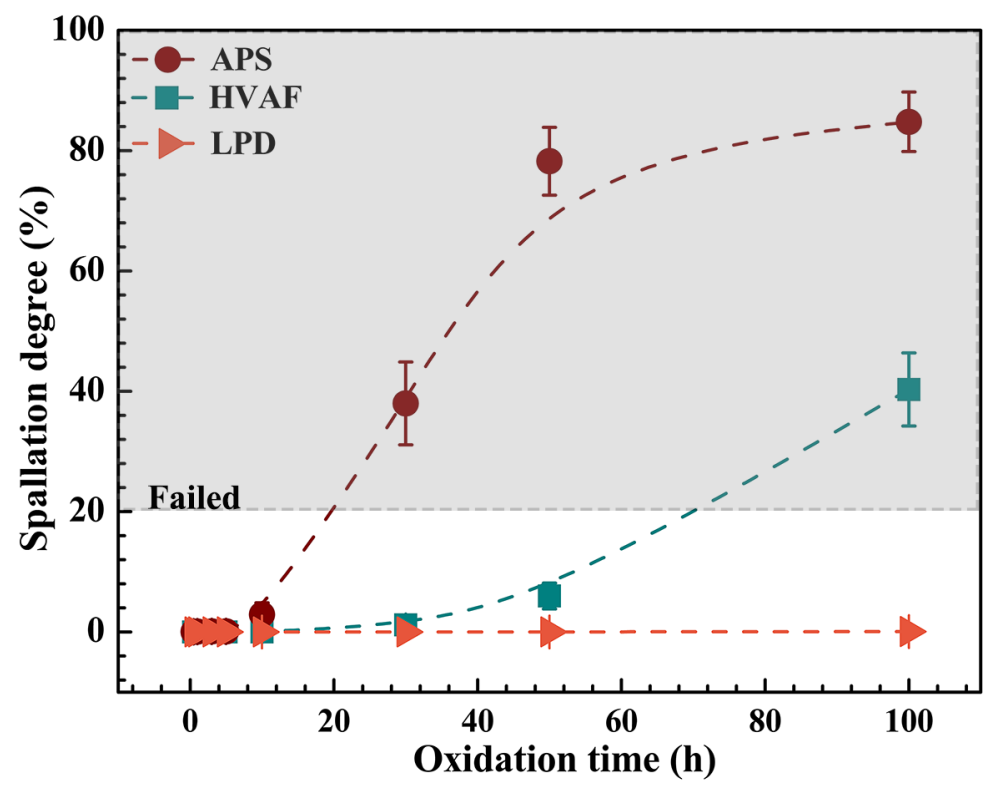

Fig. 3 The spallation degree of the oxide scales formed on the bond coats as function of isothermal oxidation time at $1150{ }^{\circ} \mathrm{C}$.

\subsection{TGO microstructure}


The TGO of APS, HVAF and LPD bond coats after isothermal oxidation at $1150{ }^{\circ} \mathrm{C}$ for $0.5 \mathrm{~h}$ shows different microstructure characteristics as presented in Fig. 4. For APS bond coat, the formation of non-uniform TGO layer can be observed. A large amount of spinel phase develops along defects such as pores and cracks. Fig. 4d shows the enlarged view of the region marked by the rectangle in Fig. 4a illustrating that the equiaxial spinel with grain size an order of magnitude larger than that of alumina is surrounded by oxides rich in $\mathrm{Cr}$ and $\mathrm{Ni}$. Besides, many pores are observed on the oxides layer, which accelerates the TGO growth rate. For HVAF bond coat, spinel grains scatter around the unmelted particle boundaries as presented in Fig. 4b. However, the LPD bond coat shows a uniform and compact TGO layer consisting mainly of $\alpha-\mathrm{Al}_{2} \mathrm{O}_{3}$. The difference in the oxidation behavior is more pronounced after longer oxidation time.

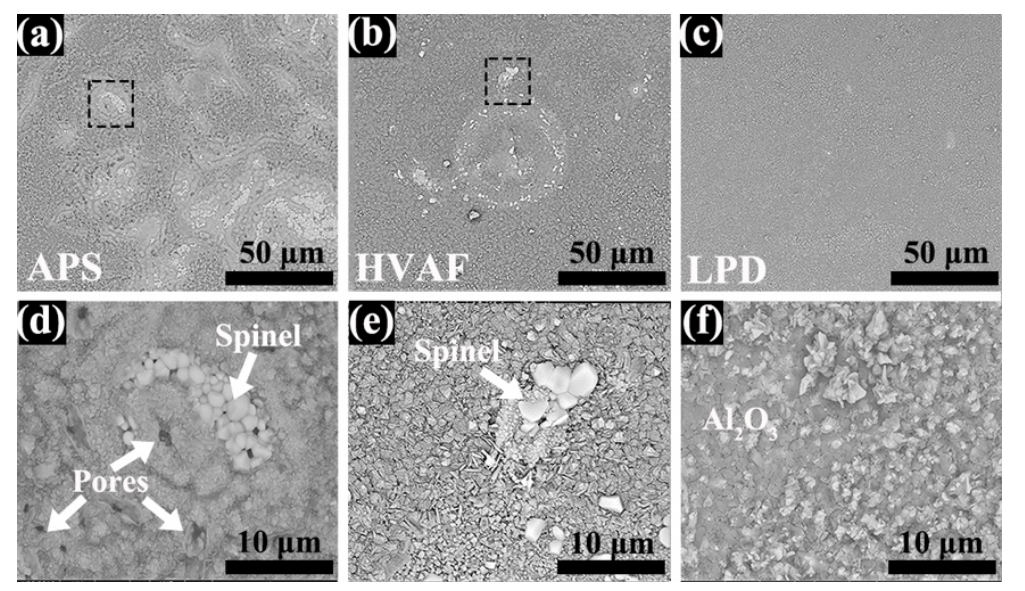

Fig. 4 Surface microstructure of the bond coats deposited by (a, d) APS, (b, e) HVAF and (c, f) LPD after isothermal oxidation at $1150{ }^{\circ} \mathrm{C}$ for $0.5 \mathrm{~h}$.

Fig. 5 shows the optical micrographs of TGO formed on the surface of APS, HVAF and LPD bond coats after exposure at $1150{ }^{\circ} \mathrm{C}$ for longer time. After oxidation for 10 h, the surface of APS bond coat (Fig. 5a) is mostly covered by blue colored oxides corresponding to spinel $\left(\mathrm{Ni}(\mathrm{Co}, \mathrm{Al})_{2} \mathrm{O}_{4}\right)$ and $\mathrm{NiO}$ [17], while for $\mathrm{HVAF}$ bond coat (Fig. 5d) there are only some blue dots scattering on the surface, and none is observed on the LPD bond coat. This observation agrees with the XRD results shown in Fig. 6 that the TGO on APS bond coat has more spinel than that on HVAF bond coat. The 
$\mathrm{NiO}$ and spinel phase exhibit higher growth rate and increase the locally compressive stress that leads to the initiation of interfacial cracks [18]. In contrast, the TGO formed on LPD coating is primary $\alpha-\mathrm{Al}_{2} \mathrm{O}_{3}$, except for a few amount of Y-rich oxides which is related to the low oxygen content in the as-deposited coatings [19, 20]. When the oxidation time reaches $50 \mathrm{~h}$, the spallation of the TGO on APS bond coat spreads all over the surface and local spallation of TGO of HVAF coatings initiates and propagates from the blue dots (spinel). It should be noted that the number density of the blue dots does not increase with the oxidation time, and the blue dots almost disappear after oxidation for $100 \mathrm{~h}$ (Fig. 5f) when the spallation area is more than $40 \%$. However, no detachment is detected on the surface of LPD bond coat after 100 $\mathrm{h}$ oxidation, except for the minor spallation around the rim of pore marked by the arrow (Fig. 5i) which is related to the tension stress caused by the curvature [21].

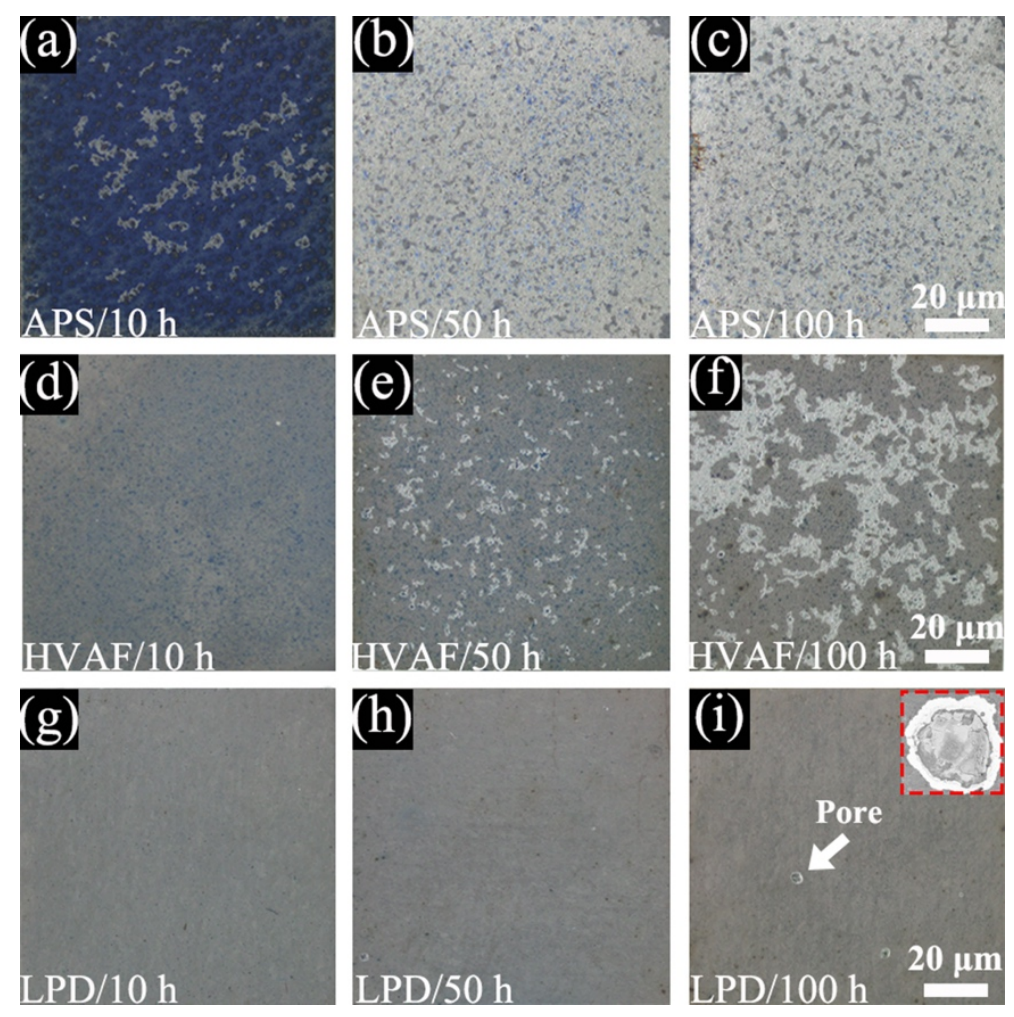

Fig. 5 The optical micrographs of the TGO formed on the APS, HVAF and LPD bond coats after isothermal oxidation at $1150{ }^{\circ} \mathrm{C}$ for $10 \mathrm{~h}, 50 \mathrm{~h}$ and $100 \mathrm{~h}$ respectively. The inset shows the enlarged view around the pore marked by the arrow. 


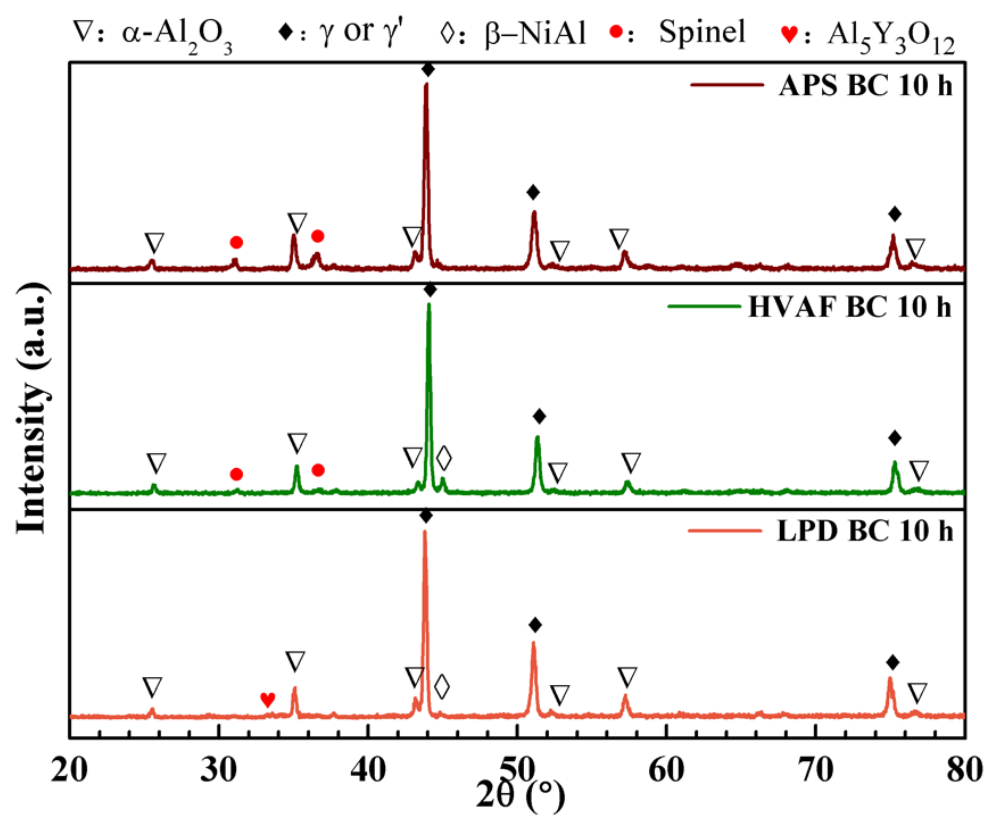

Fig. 6 The XRD results of the APS, HVAF and LPD bond coats after isothermal oxidation at $1150{ }^{\circ} \mathrm{C}$ for $10 \mathrm{~h}$.

Fig. 7 presents the surface and cross-section of the APS, HVAF and LPD bond coats when the TGO begin to spall off. It proves that the spinel prefers to form around the defects and the TGO spallation starts from this area. The internal oxidation in the APS bond coat after $10 \mathrm{~h}$ oxidation is more severe than that in the HVAF bond coat after $50 \mathrm{~h}$. The internal oxidation is believed to accelerate the Al-consumption and the premature failure of the TGO $[22,23]$. However, for the LPD bond coat, the TGO remains intact and no interfacial cracks and internal oxides are found even after $100 \mathrm{~h}$ oxidation. Meanwhile, Some Y rich oxides (defined as pegs) presents at the interface between the TGO and LPD bond coat which is thought to be beneficial as mechanically anchoring the TGO layer, therefore increasing the interfacial toughness [24]. 

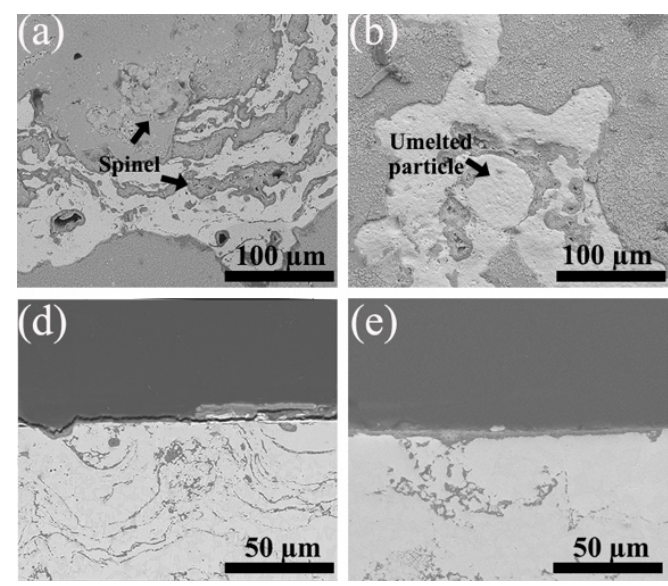
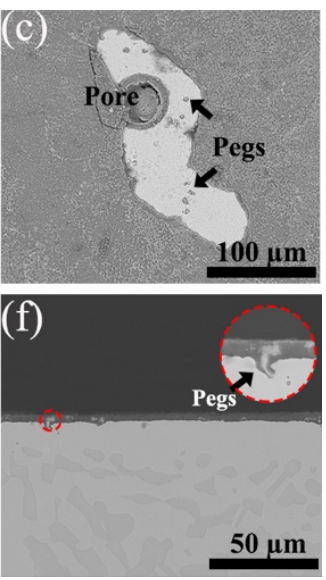

Fig. 7 The detached area and cross-section of (a, d) APS bond coat, (b, e) HVAF bond coat and (c, f) LPD bond coat after isothermal oxidation at $1150{ }^{\circ} \mathrm{C}$ for $10 \mathrm{~h}, 50 \mathrm{~h}$ and $100 \mathrm{~h}$, respectively.

Fig. 8 shows the double-layered TGO developed on the surface of the bond coats, consisting of an outer layer and a coarser grained columnar inner layer adjacent to the bond coat as a result of the concurrent inward diffusion of oxygen and outward diffusion of metal elements [25]. The out layer of TGO on APS bond coat consists of faceted equiaxed polycrystals $\left(\mathrm{NiO}\right.$ and $\left.\left.\mathrm{Ni}(\mathrm{Co}, \mathrm{Al})_{2} \mathrm{O}_{4}\right)\right)$ and pores formed between the interface of TGO/APS bond coat which is related to the volume contractions caused by the reaction between $\alpha-\mathrm{Al}_{2} \mathrm{O}_{3}$ and $\mathrm{NiO}$ [26]. While the out layer of LPD bond coat consists of granular alumina with smaller grain size, and is denser than that of the HVAF bond coat. This indicates that a smaller grain size in the LPD bond coat promotes the nucleation of alumina during the initial oxidation stage, which is crucial for decreasing the TGO growth rate and reducing the formation of other detrimental oxides. 

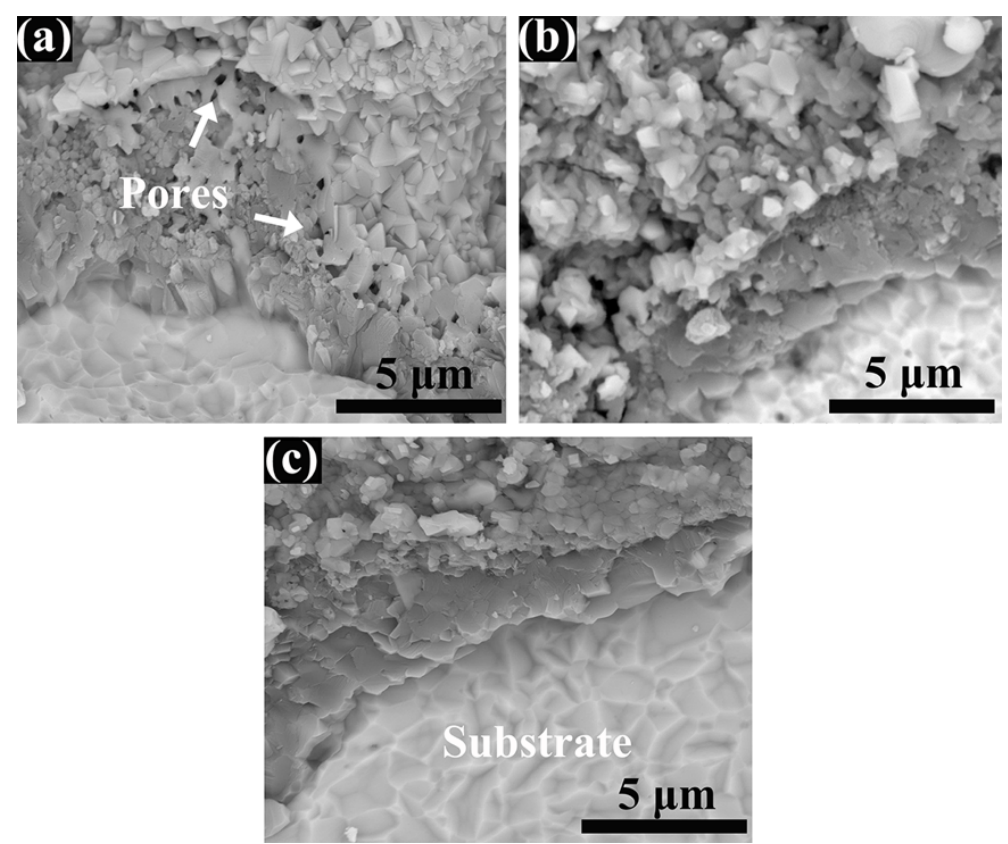

Fig. 8 The fracture cross-section of TGO on (a) APS, (b) HVAF and (c) LPD bond coats after isothermal oxidation at $1150{ }^{\circ} \mathrm{C}$ for $10 \mathrm{~h}, 50 \mathrm{~h}$ and $100 \mathrm{~h}$, respectively.

\subsection{Oxide growth kinetics}

Fig. 9 shows the TGO thickness of bond coats as a function of the time of isothermal oxidation at $1150{ }^{\circ} \mathrm{C}$. The average thickness of the oxide layers was measured at 50 equidistance points distributed over the length of the cross-section with a step size of $20 \mu \mathrm{m}$. The thickness of TGO on the APS bond coat increases dramatically and reaches $6.1 \mu \mathrm{m}$ after $10 \mathrm{~h}$ oxidation when the TGO starts to detach. This is consistent with the critical thickness (about $6 \sim 7 \mu \mathrm{m}$ ) reported earlier at which the spallation occur [27]. While the HVAF bond coat and LPD bond coat show comparable TGO thickness at the first $50 \mathrm{~h}$, but the difference between them become apparent after 100 h oxidation ( $\sim 3.4 \mu \mathrm{m}$ for LPD bond coat, $\sim 4.1 \mu \mathrm{m}$ for HVAF bond coat). In general, the TGO growth rate of bond coat prepared by HVAF and LPD is much lower than that of APS. This implies that bond coat with dense structure, low oxygen content and homogenously distributed $\beta$-NiAl phase has better oxidation resistance under the isothermal oxidation at $1150{ }^{\circ} \mathrm{C}$. 


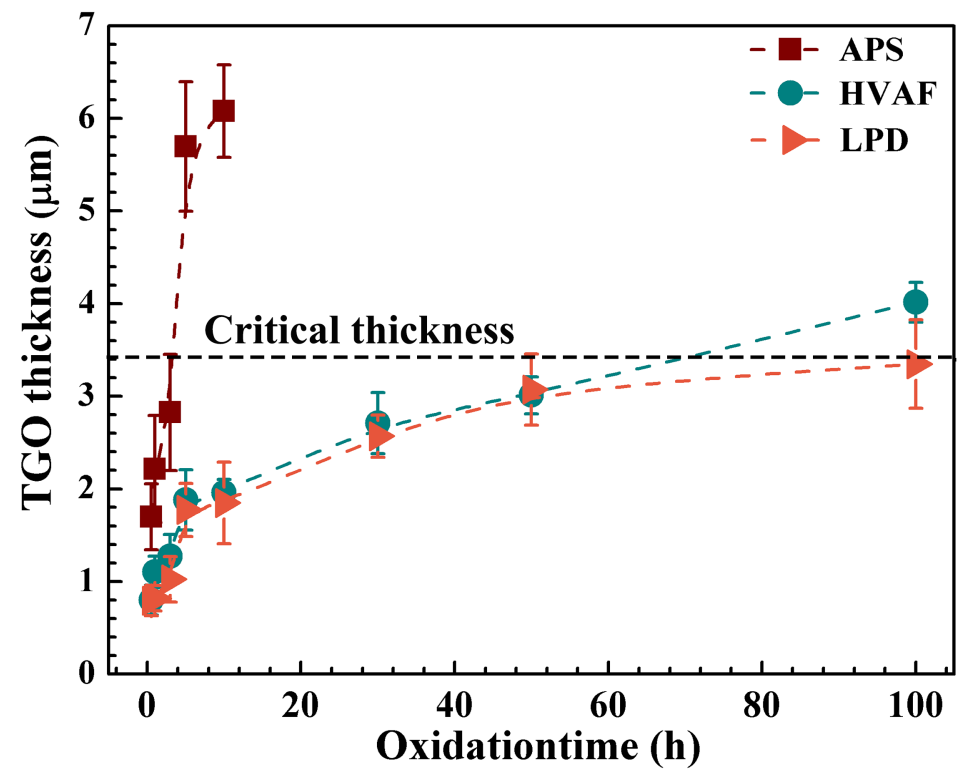

Fig. 9 Kinetics of isothermal oxidation of the APS, HVAF and LPD bond coats at $1150{ }^{\circ} \mathrm{C}$. The horizontal dash line shows the critical thickness of thermally grown oxides (TGO) layer for the propagation of the edge initiated cracks without arrest.

\subsection{TGO stress}

The surface morphology and phase composition of TGO are different around or away from the defects such as cracks and pores (Fig. 4). Around the defects, much spinel phase form which is susceptible to crack generation and propagation due to the low fracture toughness and the concentrated stress caused by locally rapid volume expansion [18]. While away from the defects, the oxides of TGO is predominately alumina. Therefore, the luminescence shift in the TGO around and away from the defects were recorded respectively to evaluate the driving force (residual stress) for spallation and to characterize the extent of any stress relaxation that occurs during the cooling. Assuming that the oxide/metal interface is flat, the residual stress $\sigma$ in TGO can be approximated to be equi-biaxial and calculated by equation [28]:

$$
\overline{\Delta v}=\frac{2}{3} \Pi_{\mathrm{ii}} \sigma
$$

where $\overline{\Delta v}$ is frequency shift of $\mathrm{R}_{2}$ fluorescence, $\Pi_{\mathrm{ii}}$ is piezospectroscopic coefficients for the $\mathrm{R}_{2}$ peak, which is $7.60 \mathrm{~cm}^{-1} / \mathrm{GPa}$ [29]. All the measurements were carried out at room temperature. The residual stress $\sigma$ includes the growth stress and thermal 
mismatch stress between TGO and bond coat during the cooling. Fig. 10 shows the evolution of the residual stress in the region away from the defects with the oxidation time ranging from $0.5 \mathrm{~h}$ to $100 \mathrm{~h}$. Every data point represented by solid symbol in the figure is obtained from separate specimens and represents the average value of 300 points with a step size of $3 \mu \mathrm{m}$. Detached area of TGO is more than $20 \%$ for the APS bond coat after $10 \mathrm{~h}$ oxidation and HVAF bond coat after $50 \mathrm{~h}$ oxidation at $1150{ }^{\circ} \mathrm{C}$, which is defined as failed. Therefore, no results of samples were recorded after failed. The data shown in Fig. 10 reveals two important features. First, the residual stress decreases for all the coatings with the oxidation time at the initial stage, which is possibly related to relaxation mechanisms such as creep [30]. Second, the TGO residual stress in LPD bond coat is much higher than that in HVAF and APS bond coast, and remains at a steady level $(\sim 5.7 \mathrm{GPa})$ after $10 \mathrm{~h}$ oxidation.

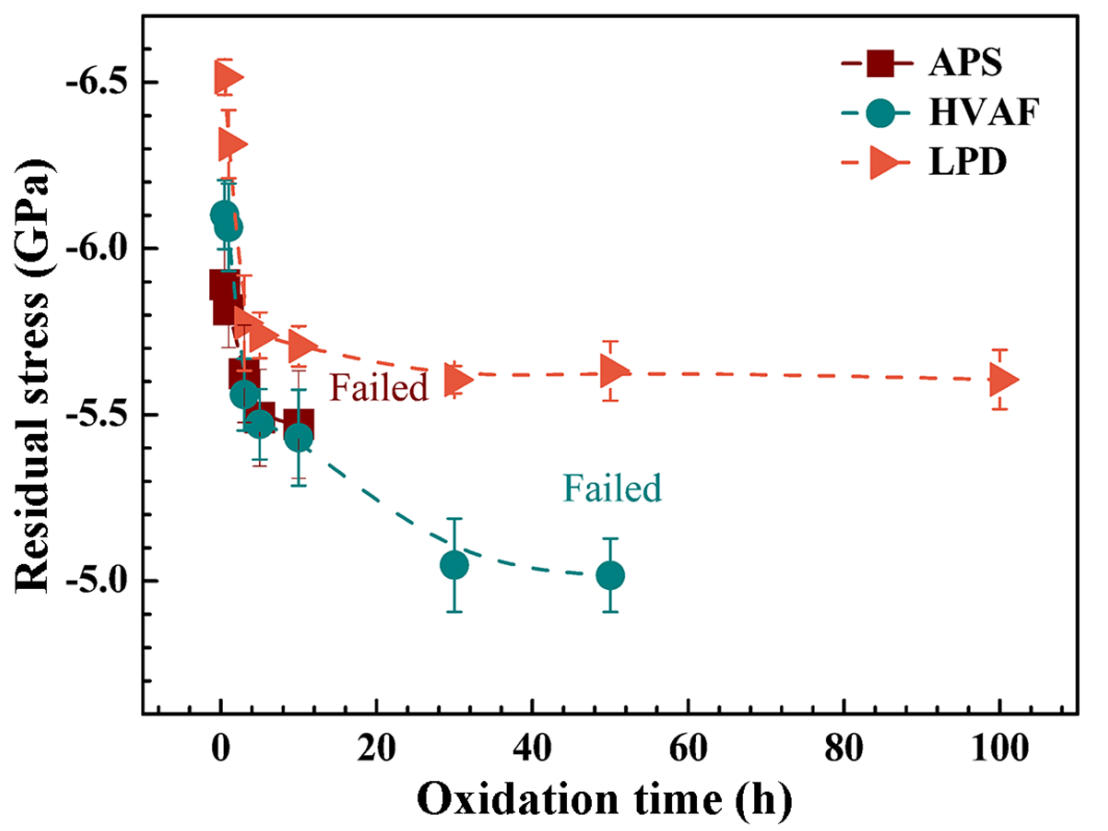

Fig. 10 The residual stress of the TGO away from the defects as function of the isothermal oxidation time at $1150^{\circ} \mathrm{C}$.

Fig. 5 and Fig. 6 show that the spallation of the TGO prefers to initiate from the defects where spinel forms on APS and HVAF bond coats, and the rim of pores on LPD bond coat. To map the residual stress distribution over the characteristic defect zone, fluorescence measurements were conducted on a grid of $200 \times 300 \mu \mathrm{m}$ with a 
step size of $3 \mu \mathrm{m}$. The residual stress distribution around the defects after $1 \mathrm{~h}$ oxidation is shown in Fig. 11. The TGO stress distribution on the APS bond coat is shown in Fig. 11b, in which the cauliflower-like blue area is in good agreement with the spinel distribution in Fig. 11 a. The cauliflower-like microstructure spinel generates along the cracks and voids is related to the as-deposited surface of the bond coat due to successive overlapping of splats. Around the spinel phase, the residual stress relaxation may attribute to the nucleation and propagation of interfacial cracks. This phenomenon also occurs on the HVAF bond coat (Fig. 11d). For LPD bond coat, the residual stress around a pore was mapped and shows that the stress is relatively lower around the rim. This may be related to the micro crack generation caused by the residual stress around the curved surface, as evidenced by areas where the spallation occurs after long time oxidation. It can be confirmed that the defects play an important role in the initiation of the TGO spallation [31]. The LPD bond coat with homogenous $\alpha-\mathrm{Al}_{2} \mathrm{O}_{3}$ layer is beneficial for stable adhesion.
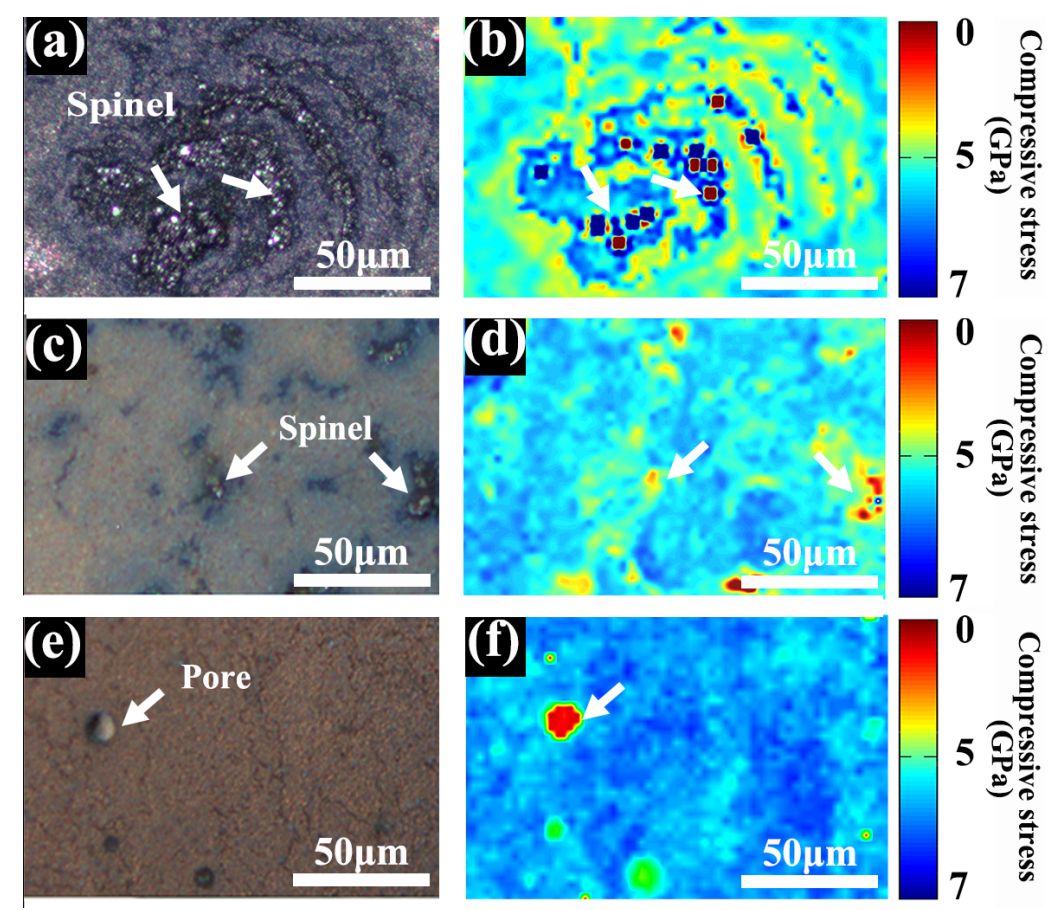

Fig. 11 The optical micrographs and residual stress distribution around the characteristic area on the surface of (a, b) APS bond coat, (c, d) HVAF bond coat and (e, f) LPD bond coat after isothermal oxidation at $1150^{\circ} \mathrm{C}$ for $1 \mathrm{~h}$. 


\section{Discussion}

\subsection{Effect of microstructures on TGO growth rate}

The growth rate of the TGO plays an important role in the durability of the TGO/bond coat system. Fig. 8 illustrates that the TGO growth rate on APS bond coat is higher than that on HVAF and LPD bond coats. The fast growth of the TGO on APS bond coat could be attributed to the following factors. First, a large number of pores and micro-cracks within the APS bond coat provide infiltration paths for metal elements and additional surface area for oxidation, allowing spinel to occur around the defects [32]. In turn the spinel is porous and gives the ease of the inward diffusion of oxygen and outward diffusion of metal element, resulting in higher TGO growth rate [33]. Furthermore, the severe internal oxidation accelerates Al depletion and the internally formed oxides hinder the outward diffusion of aluminum, resulting in the formation of spinel [34]. Therefore, bond coats with high oxygen content and more cracks that provide diffusion paths for oxygen, are susceptible to internal oxidation at higher concentration of Al. This is consistent with the observation that APS bond coat suffers the most severe internal oxidation at early oxidation stage, followed by HVAF bond coat and no internal oxidation is found in the LPD bond coat. The TGO thickness on HVAF bond coat is almost the same as the LPD bond coat by the first $50 \mathrm{~h}$, but difference increases with proceeding oxidation. This could be attributed to that the $\mathrm{Al}$ content in HAVF bond coat is sufficient for the selective oxidation at early stage, but the continuous consumption by TGO growth and internal oxidation leads to a higher depletion rate of Al. Then, non-protective oxides form within the Al-depleted zone, resulting in a fast growth of the TGO, as indicated by the surface micrographs that spinel phases scatter on the surface near the defects (Fig. 4b). For the LPD bond coat, a homogeneous alumina layer forms without detectable internal oxides and spinel phase, which can be attributed to the following factors. First, the well distributed $\beta$-NiAl phase that increases the phase-boundary area could enhance aluminum diffusion, thus promotes the formation of the dense alumina [16]. Second, the dense and defect-free microstructure associated with low oxygen content in the coating hinder the occurrence of detrimental phase such as spinel and $\mathrm{NiO}$, and internal oxidation. Therefore, the LPD bond coat shows better oxidation resistance compared with APS and HVAF bond coats after isothermal oxidation at $1150{ }^{\circ} \mathrm{C}$. 


\subsection{Effect of microstructures on TGO stress}

The Fig. 10 shows that residual stress in TGO on the LPD bond coat remains $5.7 \mathrm{GPa}$ after long-time oxidation, which is much higher than that of APS and HVAF bond coats. The residual stress in TGO stress on the APS and HVAF bond coats decreases with the oxidation time until the TGO fail. This can be attributed to the development of the interfacial cracks. The stress of the TGO around the imperfections is released since the early oxidation stage $(1 \mathrm{~h})$. The spinel is porous, brittle and its growth rate is almost three orders of magnitude higher than that of alumina [18]. The local volume expansion caused by the fast growth of spinel leads to compressive local stress, making it easier for crack nucleation and propagation. This is proved by the spallation behavior that the detachment of the TGO initiates from the spinel area, as shown in Fig. 7. While, the residual stress in TGO on the LPD bond coat keeps constant after $10 \mathrm{~h}$. This means no stress relaxation processes such as creep, crack generation and propagation occur during the subsequent oxidation, which is supported by the intact interface shown in Fig. $7 \mathrm{f}$ and the results of spallation degree shown in Fig. 3. Therefore, the higher and more homogenously distributed compressive stress indicates the mechanical stability of the TGO $[35,36]$.

\subsection{Spallation behavior}

Based on Fig. 4, the TGO on the bond coats deposited by different methods shows different failure pattern. For APS and HVAF bond coats, the TGO detachment begin around the defects (e.g., cracks and pores) where the spinel phase prefers to develop. Subsequently, the spallation of the TGO spreads all over the surface with an increase of the oxidation time. For the LPD bond coat, the TGO is mostly intact expect for minor detachment around the rim of pores. The reasons for the different failure behavior will be proposed as follows.

For compressed coating system, two competing failure mechanisms are edge and buckle driven delamination $[31,37]$. When subjected to equi-biaxial compressive stress $\sigma$, elastic strain energy is stored in the film. The associated energy release rate $G$ 
in the coating is:

$$
G=\frac{\sigma^{2} h_{\mathrm{ox}}\left(1-v_{\mathrm{ox}}\right)}{2 E_{\mathrm{ox}}}
$$

where the $h_{\mathrm{ox}}, v_{\mathrm{ox}}$ and $E_{\mathrm{ox}}$ are the thickness, Poisson's ration and Young's modulus of the TGO layer, respectively.

If the coatings fail by buckling, then a pre-existing interface separation that exceeds the critical diameter $d_{\mathrm{c}}$ between the bond coat and TGO is required. Then the critical diameter of interfa cial separation $d_{\mathrm{c}}$ for buckling from the interface is given by [38]:

$$
d_{\mathrm{c}}=\sqrt{\frac{4.88 E_{\mathrm{ox}} h_{\mathrm{ox}}^{2}}{\left(1-v^{2}\right) \sigma}}
$$

With $E_{\mathrm{ox}}=380 \mathrm{GPa}, v_{\mathrm{ox}}=0.25$ and $\sigma=5.7 \mathrm{GPa}$, the estimated critical diameter $d_{\mathrm{c}}$ is about 24 times of the TGO thickness [39].

It is reported that if the cracks nucleate and propagate from the edge, the release rate will approach a steady state and become independent of the length of cracks when the crack length is several times of the TGO thickness [40]. The tip of the steady-state interface crack is in mode II. For simplicity, the frictional sliding is not considered. Thus, if the energy release rate $G$ exceeds the mode II interfacial toughness $\Gamma_{\mathrm{i}}^{\mathrm{II}}$, the interface cracks will propagate without arrest. Then the critical TGO thickness for edge delamination is [31]:

$$
h_{\mathrm{ox}}^{\mathrm{c}}=\frac{2 E_{\mathrm{ox}} \Gamma_{\mathrm{i}}^{\mathrm{II}}}{\sigma^{2}\left(1-v_{\mathrm{ox}}\right)}
$$

considering the mode II toughness $\Gamma_{\mathrm{i}}^{\mathrm{II}}=80 \mathrm{~J} / \mathrm{m}^{2}$ [41], and the measured stress $5.7 \mathrm{GPa}$ shown in Fig. 10, the critical thickness $h_{\mathrm{ox}}^{\mathrm{c}}$ is about $3.4 \mu \mathrm{m}$. It indicates that the edge delamination will be dominating if the TGO thickness exceeds the critical thickness. For the TGO/APS bond coat, the cracks primarily nucleate around the defects [42]. Due to the high density of defects in the APS bond coat, the interfacial cracks coalesce easily, causing the premature failure of TGO. For the HVAF bond coat, the 
TGO first detaches at the weak region where spinel forms. The detached area creates new edge and then the TGO fails through edge delamination. This agrees with the calculated results of critical TGO thickness for edge delamination, as shown in Fig. 9. When the TGO thickness is lower than the critical thickness (oxidation for $50 \mathrm{~h}$ ), only locally detachment appears around the spinel phases (Fig. 5e). Once the TGO thickness exceeds the critical thickness (oxidation for $100 \mathrm{~h}$ ), large area detachment occurs (Fig. 5f). However, the TGO on the LPD coating is uniform, continuous and primarily composed of $\alpha-\mathrm{Al}_{2} \mathrm{O}_{3}$. Therefore, the TGO layer can only fail through buckling with the diameter of pre-exist interfacial crack exceeding 24 times of the TGO thickness $(\sim 72 \mu \mathrm{m})$. While the good adherence and low growth rate of TGO inhibits the formation of interfacial cracks. Therefore, the TGO keeps intact with LPD bond coat. This could be the reason why LPD bond coat shows better TGO spallation resistance than the HVAF bond coat in spite of the comparable thickness between them under the isothermal treatment at $1150{ }^{\circ} \mathrm{C}$.

In general, the exceptional TGO spallation resistance for the LPD coating could be attributed to the formation of a uniform, compact and low growth rate alumina layer and enhanced interface toughness caused by the formation of oxide pegs, and benefit from the defect-free microstructure, the low oxygen content and well distributed $\beta$-NiAl phase [43].

\section{Conclusions}

In this study, we develop a laser powder deposition (LPD) method to fabricate the NiCoCrAlY bond coat for the thermal barrier coating application. The microstructure, oxidation kinetics, spallation behavior and residual stress of the thermally grown oxides (TGO) layer are investigated and compared with those fabricated by the air plasma spray (APS) and high velocity air fuel (HVAF). The following conclusions can be made:

1. The bond coat prepared by laser powder deposition exhibits dendritic microstructure and lower defects density with the average porosity of $0.32 \%$ 
which is much lower than the bond coats prepared by air plasma spray $(10.7 \%)$ and high velocity air fuel (3.32\%).

2. The TGO formed on the bond coat prepared by laser powder deposition is predominantly $\alpha-\mathrm{Al}_{2} \mathrm{O}_{3}$, except for some $\mathrm{Y}$ rich oxides (pegs) which is considered beneficial for the interfacial adhesion. While for the bond coats prepared by air plasma spray and high velocity air fuel method, undesirable spinel phases, e.g., $\mathrm{Ni}(\mathrm{Co}, \mathrm{Al})_{2} \mathrm{O}_{4}$, forms around the defects during the early stage of oxidation.

3. The isothermal oxidation tests at $1150{ }^{\circ} \mathrm{C}$ demonstrate that the bond coat prepared by laser powder deposition shows much better spallation resistance. The spallation degree of the bond coats prepared by air plasma spray and high velocity air fuel method is more than $80 \%$ and $40 \%$ respectively after $100 \mathrm{~h}$ oxidation. However, the TGO on the bond coat prepared by the laser powder deposition is almost intact. The defects had significant effect on the stability of the TGO.

4. The bond coat prepared by laser powder deposition exhibits the best oxidation resistance after isothermal oxidation tests at $1150{ }^{\circ} \mathrm{C}$, compared with bond coat prepared by air plasma spray and high velocity air fuel method. The dense microstructure, well distributed $\beta-\mathrm{NiAl}$ phase and low oxygen content are beneficial for the formation of compact and low growth rate TGO.

5. The TGO residual stress of the bond coat prepared by laser powder deposition remained at a steady level which is higher than that of bond coats deposited by air plasma spray and high velocity air fuel method, indicating good adherence between the TGO and bond coat. The stress distribution around the defects illustrates that the stress prefers to release in this region by cracks nucleation and propagation.

In summary, the laser powder deposition is a promising method for fabricating high performance bond coat for the thermal barrier coating application. It produces a uniform and compact alumina oxide with low growth rate and high spallation resistance than conventional techniques. However, the depth of the melt pool should 
be minimized to avoid the detrimental effects on the underlying superalloy substrate.

\section{Acknowledgement}

The authors wish to thank the National Natural Science Foundation of China (No. 51271120 and No. 51402058 ).

\section{References}

[1] D.R. Clarke, C.G. Levi, Materials design for the next generation thermal barrier coatings, Annu. Rev. Mater. Res. 33 (2003) 383-417.

[2] V.K. Tolpygo, D.R. Clarke, On the rumpling mechanism in nickel-aluminide coatings: Part I: an experimental assessment, Acta. Mater. 52 (2004) 5115-5127.

[3] A.G. Evans, M.Y. He, J.W. Hutchinson, Mechanics-based scaling laws for the durability of thermal barrier coatings, Prog. Mater. Sci. 46 (2001) 249-271.

[4] L. Qiu, F. Yang, W. Zhang, X. Zhao, P. Xiao, Effect of Al content on the lifetime of thermally grown oxide formed on $\mathrm{Ni}-\mathrm{Al}$ alloys after isothermal oxidation, Corros. Sci. 89 (2014) 13-20.

[5] K. Messaoudi, A.M. Huntz, B. Lesage, Diffusion and growth mechanism of $\mathrm{Al}_{2} \mathrm{O}_{3}$ scales on ferritic Fe-Cr-Al alloys, Mater. Sci. Eng. A. 247 (1998) 248-262.

[6] S. Salam, P.Y. Hou, Y.D. Zhang, H.F. Wang, C. Zhang, Z.G. Yang, Compositional effects on the high-temperature oxidation lifetime of MCrAlY type coating alloys, Corros. Sci. 95 (2015) 143-151.

[7] G. Mauer, M. Jarligo, D. Mack, R. Vaßen, Plasma-Sprayed Thermal Barrier Coatings: New Materials, Processing Issues, and Solutions, J. Therm. Spray. Tech. 22 (2013) 646-658.

[8] P. Song, D. Naumenko, R. Vassen, L. Singheiser, W.J. Quadakkers, Effect of oxygen content in NiCoCrAlY bondcoat on the lifetimes of EB-PVD and APS thermal barrier coatings, Surf. Coat. Tech. 221 (2013) 207-213.

[9] P. Richer, M. Yandouzi, L. Beauvais, B. Jodoin, Oxidation behaviour of CoNiCrAlY bond coats produced by plasma, HVOF and cold gas dynamic spraying, Surf. Coat. Tech. 204 (2010) 3962-3974. 
[10] S. Sun, Y. Durandet, M. Brandt, Parametric investigation of pulsed Nd: YAG laser cladding of stellite 6 on stainless steel, Surf. Coat. Tech. 194 (2005) 225-231.

[11] C. Bezencon, A. Schnell, W. Kurz, Epitaxial deposition of MCrAlY coatings on a Ni-base superalloy by laser cladding, Script. Mater. 49 (2003) 705-709.

[12] Y.N. Wu, G. Zhang, Z.C. Feng, B.C. Zhang, Y. Liang, F.J. Liu, Oxidation behavior of laser remelted plasma sprayed $\mathrm{NiCrAlY}$ and $\mathrm{NiCrAlY}-\mathrm{Al}_{2} \mathrm{O}_{3}$ coatings, Surf. Coat. Tech. 138 (2001) 56-60.

[13] J.C. Pereira, J.C. Zambrano, M.J. Tobar, A. Yanez, V. Amigó, High temperature oxidation behavior of laser cladding MCrAlY coatings on austenitic stainless steel, Surf. Coat. Tech. 270 (2015) 243-248.

[14] K. Partes, C. Giolli, F. Borgioli, U. Bardi, T. Seefeld, F. Vollertsen, High temperature behaviour of NiCrAlY coatings made by laser cladding, Surf. Coat. Tech. 202 (2008) 2208-2213.

[15] S. Deshpande, A. Kulkarni, S. Sampath, H. Herman, Application of image analysis for characterization of porosity in thermal spray coatings and correlation with small angle neutron scattering, Surf. Coat. Tech. 187 (2004) 6-16.

[16] L. Ajdelsztajn, F. Tang, J.M. Schoenung, G.E. Kim, V. Provenzano, Synthesis and oxidation behavior of nanocrystalline MCrAlY bond coatings, J. Therm. Spray. Tech. 14 (2005) 23-30.

[17] K.P. Trumble, M. Rühle, The thermodynamics of spinel interphase formation at diffusion-bonded $\mathrm{Ni} / \mathrm{Al}_{2} \mathrm{O}_{3}$ interfaces, Acta. Mater. 39 (1991) 1915-1924.

[18] Y. Li, C.-J. Li, Q. Zhang, G.-J. Yang, C.-X. Li, Influence of TGO Composition on the Thermal Shock Lifetime of Thermal Barrier Coatings with Cold-sprayed MCrAlY Bond Coat, J. Therm. Spray. Tech. 19 (2009) 168-177.

[19] T.J. Nijdam, L.P.H. Jeurgens, J.H. Chen, W.G. Sloof, On the Microstructure of the Initial Oxide Grown by Controlled Annealing and Oxidation on a NiCoCrAlY Bond Coating, Oxid. Met. 64 (2005) 355-377.

[20] F.H. Yuan, Z.X. Chen, Z.W. Huang, Z.G. Wang, S.J. Zhu, Oxidation behavior of thermal barrier coatings with HVOF and detonation-sprayed NiCrAlY bondcoats, Corros. Sci. 50 (2008) 1608-1617. 
[21] D.R. Clarke, W. Pompe, Critical radius for interface separation of a compressively stressed film from a rough surface, Acta. Mater. 47 (1999) 1749-1756.

[22] D. Renusch, M. Schorr, M. Schütze, The role that bond coat depletion of aluminum has on the lifetime of APS-TBC under oxidizing conditions, Mater. Corros. 59 (2008) 547-555.

[23] M. Andritschky, P. Alpuim, D. Stover, C. Funke, Study of the mechanics of the delamination of ceramic functional coatings, Mater. Sci. Eng. A. 271 (1999) 62-69.

[24] R.J. Christensen, V.K. Tolpygo, D.R. Clarke, The influence of the reactive element yttrium on the stress in alumina scales formed by oxidation, Acta. Mater. 45 (1997) 1761-1766.

[25] J.A. Nychka, D.R. Clarke, Quantification of Aluminum Outward Diffusion During Oxidation of FeCrAl Alloys, Oxid. Met. 63 (2005) 325-352.

[26] Y. Chen, X. Zhao, M. Bai, A. Chandio, R. Wu, P. Xiao, Effect of platinum addition on oxidation behaviour of $\gamma / \gamma^{\prime}$ nickel aluminide, Acta. Mater. 86 (2015) 319-330.

[27] V.K. Tolpygo, D.R. Clarke, K.S. Murphy, Oxidation-induced failure of EB-PVD thermal barrier coatings, Surf. Coat. Tech. 146 (2001) 124-131.

[28] E.A.G. Shillington, D.R. Clarke, Spalling failure of a thermal barrier coating associated with aluminum depletion in the bond-coat, Acta. Mater. 47 (1999) 1297-1305.

[29] J. He, D.R. Clarke, Determination of the Piezospectroscopic Coefficients for Chromium-Doped Sapphire, J. Am. Ceram. Soc. 78 (1995) 1347-1353.

[30] V.K. Tolpygo, D.R. Clarke, Alumina scale failure resulting from stress relaxation, Surf. Coat. Tech. 120 (1999) 1-7.

[31] J.W. Hutchinson, M.Y. He, A.G. Evans, The influence of imperfections on the nucleation and propagation of buckling driven delaminations, J. Mech. Phys. Solid. 48 (2000) 709-734.

[32] Y. Li, C.J. Li, G.J. Yang, L.K. Xing, Thermal fatigue behavior of thermal barrier coatings with the MCrAlY bond coats by cold spraying and low-pressure plasma spraying, Surf. Coat. Tech. 205 (2010) 2225-2233. 
[33] J.S. Wang, A.G. Evans, Measurement and analysis of buckling and buckle propagation in compressed oxide layers on superalloy substrates, Acta. Mater. 46 (1998) 4993-5005.

[34] H.E. Evans, M.P. Taylor, Diffusion Cells and Chemical Failure of MCrAlY Bond Coats in Thermal Barrier Coating Systems, Oxid. Met. 55 (2001) 17-34.

[35] E.P. Busso, H.E. Evans, Z.Q. Qian, M.P. Taylor, Effects of breakaway oxidation on local stresses in thermal barrier coatings, Acta. Mater. 58 (2010) 1242-1251.

[36] V.K. Tolpygo, D.R. Clarke, K.S. Murphy, Oxidation-induced failure of EB-PVD thermal barrier coatings, Surf. Coat. Tech. 146 (2001) 124-131.

[37] J.W. Hutchinson, Z. Suo, Mixed Mode Cracking in Layered Materials, Adv. Appl. Mech. 29 (1991) 63-191.

[38] V.K. Tolpygo, D.R. Clarke, Spalling failure of alpha-alumina films grown by oxidation. II. Decohesion nucleation and growth, Mater. Sci. Eng. A. 278 (2000) $151-161$.

[39] L.T. Wu, R.T. Wu, X. Zhao, P. Xiao, Microstructure parameters affecting interfacial adhesion of thermal barrier coatings by the EB-PVD method, Mater. Sci. Eng. A. 594 (2014) 193-202.

[40] S.R. Choi, J.W. Hutchinson, A.G. Evans, Delamination of multilayer thermal barrier coatings, Mech. Mater. 31 (1999) 431-447.

[41] T. Xu, S. Faulhaber, C. Mercer, M. Maloney, A. Evans, Observations and analyses of failure mechanisms in thermal barrier systems with two phase bond coats based on NiCoCrAlY, Acta. Mater. 52 (2004) 1439-1450.

[42] E.P. Busso, J. Lin, S. Sakurai, M. Nakayama, A mechanistic study of oxidation-induced degradation in a plasma-sprayed thermal barrier coating system. Part I: Model formulation, Acta. Mater. 49 (2001) 1515-1528.

[43] B.G. Mendis, K.J.T. Livi, K.J. Hemker, Observations of reactive element gettering of sulfur in thermally grown oxide pegs, Script. Mater. 55 (2006) 589-592. 